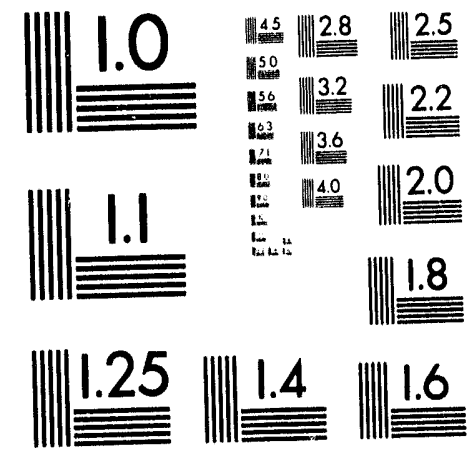



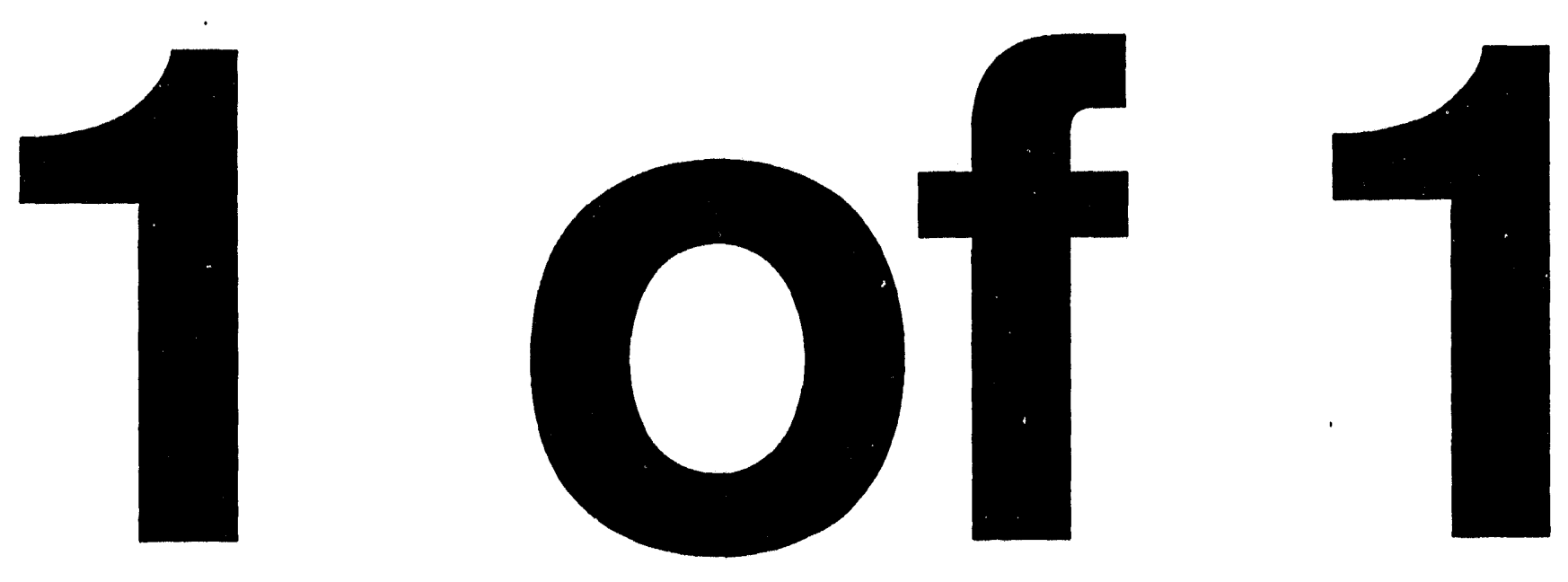
A CALCIUM OXIDE SORBENT PROCESS

FOR BULK SEPARATION OF CARBON DIOXIDE

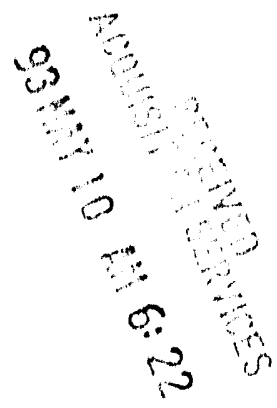

Contract No. DE-AC21-89MC26366

$$
\begin{aligned}
& \text { Quarterly Progress Report } 15 \\
& \text { January } 1993 \text { - March } 1993
\end{aligned}
$$

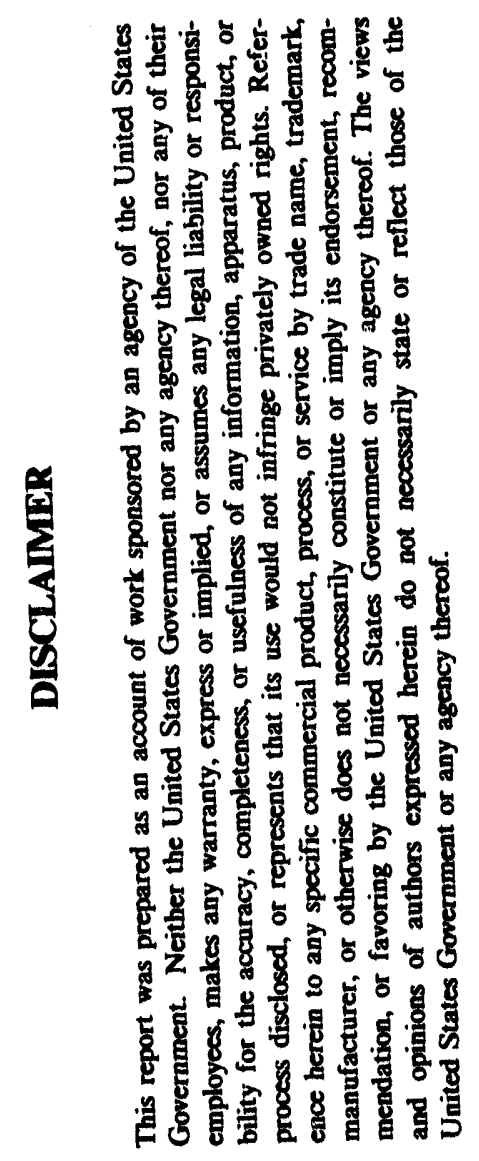
Department of Chemical Engineering Louisiana State University

Baton Rouge, Louisiana 70803

(504) 388-1426

Douglas P. Harrison

Principal Investigator

April 1993
"LCElW

OCT 011933

OSTI 
Phase II research involves a scale-up from microgram to gram quantities of sorbent and a switch from the electrobalance reactor to a fixed-bed reactor with capability for feed and product gas analysis. At the end of the previous quarter, a tentative method of product gas analysis involving only the thermal conductivity detector had been developed and the chromatograph had been calibrated using standard gas mixtures of known composition. The fixed-bed reactor system had been completed and a single reaction test involving the calcination of dolomite had been completed.

This report discusses our continuing effort to refine the chromatograph analytical technique. A simpler analytical method requiring two columns (instead of three) and one sampling valve (instead of two) is currently being used. The nickel-catalyzed methanizer has been replaced by a ruthenium-catalyzed methanizer. Because of its lower operating temperature the ruthenium system is less prone to fouling due to carbon deposition. With the methanizer, the flame ionization detector can be used for $\mathrm{CO}$ and $\mathrm{CO}_{2}$ analysis, thus providing improved sensitivity for these compounds.

A number of reaction tests involving one complete calcination/ carbonation cycle were completed during the quarter. The feed gas for these tests consisted of $\mathrm{CO}_{2}$ in $\mathrm{N}_{2}$. Standard $\mathrm{CO}_{2}$ breakthrough curves were obtained, thereby proving the ability of the calcined dolomite to remove $\mathrm{CO}_{2}$ at the temperatures and pressure of interest. Near the end of the quarter, three tests in which the feed gas contained water (steam) as well as $\mathrm{CO}_{2}$ and $\mathrm{N}_{2}$ were completed. While no quantitative data was obtained from the tests because of gas leaks, we did confirm that steam injection was feasible. In addition, small quantities of $\mathrm{H}_{2}$ 
EXECUTIVE SUMMARY

This research project is investigating the technical feasibility of a high-temperature, high-pressure (HTHP) process for the bulk separation of $\mathrm{CO}_{2}$ from coal-derived gas. The original contract for two years was awarded in september 1989 as a result of solicitation number DE-RÁ21-89MC26040 entitled "Novel Concepts for Bulk Separation of Gases in Coal Gasification Systems." Two no-cost extensions without a change in the statement of work extended the performance period by six months to March 1992. At that time a two-year contract extension with an enlarged scope of work and additional funding was approved so that the research is now scheduled to end in March 1994.

Phase I research, in which an electrobalance reactor was used to establish the technical feasibility of the regenerable sorbent process, was completed in March 1992 and results have been fully described in earlier quarterly reports. In Phase I, the calcination and carbonation characteristics of three calcium sorbents were studied as a function of calcination and carbonation temperature and pressure, mol fraction $\mathrm{CO}_{2}$ in the carbonation gas, and carbonation background gas composition. Desirable reaction conditions required for high reactivity and good sorbent durability were determined. Multicycle tests consisting of as many as ten complete calcination and carbonation cycles were completed. Indirect evidence which suggested that the water-gas shift reaction occurred simultaneously with $\mathrm{CO}_{2}$ removal was found. Occurrence of the simultaneous reactions created the possibility of a direct one-step process for the manufacture of hydrogen from coal-gas while at the same time separating a concentrated stream of $\mathrm{CO}_{2}$. The concentrated $\mathrm{CO}_{2}$ stream could be quite significant if, in the future, environmental regulations restrict atmospheric $\mathrm{CO}_{2}$ emissions. 
were detected in the reactor product. Presumably the $\mathrm{H}_{2}$ was formed as a result of the following pair of reactions

$$
\begin{aligned}
& \mathrm{C}(\mathrm{s})+\mathrm{CO}_{2}(\mathrm{~g}) \rightarrow 2 \mathrm{CO}(\mathrm{g}) \\
& \mathrm{CO}(\mathrm{g})+\mathrm{H}_{2} \mathrm{O}(\mathrm{g}) \rightarrow \mathrm{CO}_{2}(\mathrm{~g})+\mathrm{H}_{2}(\mathrm{~g})
\end{aligned}
$$

Small concentrations of $\mathrm{CO}$ had been detected in earlier tests involving $\mathrm{CO}_{2} / \mathrm{N}_{2}$ feed. The presence of product $\mathrm{H}_{2}$ therefore confirmed that the water-gas shift reaction would occur at the conditions of interest.

\section{ANALYTICAL PROCEDURE}

At the beginning of the present quarter, the method used for product gas analysis required three chromatograph columns, two automated multi-port gas sampling valves, and the thermal conductivity detector (TCD). Use of the flame ionization detector (FID) had been temporarily suspended because of the extreme sensitivity of the nickel-catalyzed methanizer which converted $\mathrm{CO}$ and $\mathrm{CO}_{2}$ to $\mathrm{CH}_{4}$ for subsequent FID analysis. Although the method appeared to be quite reliable, it did not have the desired sensitivity for low concentrations of $\mathrm{CO}$ and $\mathrm{CO}_{2} . \mathrm{A}$ complete description of the analytical method being used at the beginning of the quarter was presented in the previous quarterly report.

Several changes were made in the analytical method during the quarter. A new column, Carboxen 1000 ( $\mathrm{CBX}$ ), capable of separating $\mathrm{H}_{2}$ ' $\mathrm{N}_{2}$, CO, and $\mathrm{CO}_{2}$ was installed. This sjingle column replaced the previous Hayesep $Q$ and mol sieve columns, and also eliminated the need for the six-port gas sampling valve. The original nickel-catalyzed methanizer was replaced with a more robust ruthenium-catalyzed methanizer. Since ruthenium catalyzes the methanation reaction at a lower temperature, the problem of catalyst fouling due to carbon deposition was lessened. 
Availability of the methanizer permitted us to use the FID, and improve the analytical sensitivity for low concentrations of $\mathrm{CO}$ and $\mathrm{CO}_{2}$. Finally a three-way valve was installed between the TCD and the methanizer. This valve permits us to bypass the methanizer and FID when the product gas contains high concentrations of $\mathrm{CO}$ and $\mathrm{CO}_{2}$, and then switch the methanizer and FID into the analytical train when low $C O$ and $\mathrm{CO}_{2}$ concentrations are expected.

The new sampling and separation arrangement is shown in Figure 1. Valve vo determines whether the reactor feed or product gas is being sampled. With vo in the position shown, reactor product is sampled. In step 1, reactor product enters the ten-port sampling valve (V1), flows through the sample loop, and to vent. Primary argon carrier gas (C1) enters V1 and flows, in turn, through the carboxen 1000 column (CBX), the thermal conductivity detector (TCD) and then either through the methanizer and flame ionization detector (FID) to vent, or directly to vent from the TCD. Secondary argon carrier gas enters V1 and flows through the Hayesep $\mathbf{N}$ (HSN) column and to vent.

Sampling is initiated by switching $\mathrm{V} 1$ to the position indicated in step 2. Reactor product now flows directly into and out off $\mathrm{V} 1$ to vent. Primary carrier $\mathrm{C} 1$ picks up the sample from the sample loop and flows into $\mathrm{HSN}$ where trace $\mathrm{H}_{2} \mathrm{O}$ which escaped condensation is trapped. Argon plus $\mathrm{H}_{2}, \mathrm{~N}_{2}, \mathrm{CO}$ and $\mathrm{CO}_{2}$ pass through $\mathrm{HSN}$ to $\mathrm{CBX}$ where separation of the four reactor products occurs. Reactor products are eluted in the order $\mathrm{H}_{2}, \mathrm{~N}_{2}, \mathrm{CO}$, and $\mathrm{CO}_{2}$ and transported by $\mathrm{Cl}$ to the analytical train. Analysis of $\mathrm{H}_{2}, \mathrm{~N}_{2}$, and high concentrations of $\mathrm{CO}$ and $\mathrm{CO}_{2}$ is accomplished using the TCD. Low concentrations of $\mathrm{CO}$ and $\mathrm{CO}_{2}$ are analyzed using the more sensitive FID. Secondary carrier gas C2 flows into and out of $V 1$ to vent during this step. 


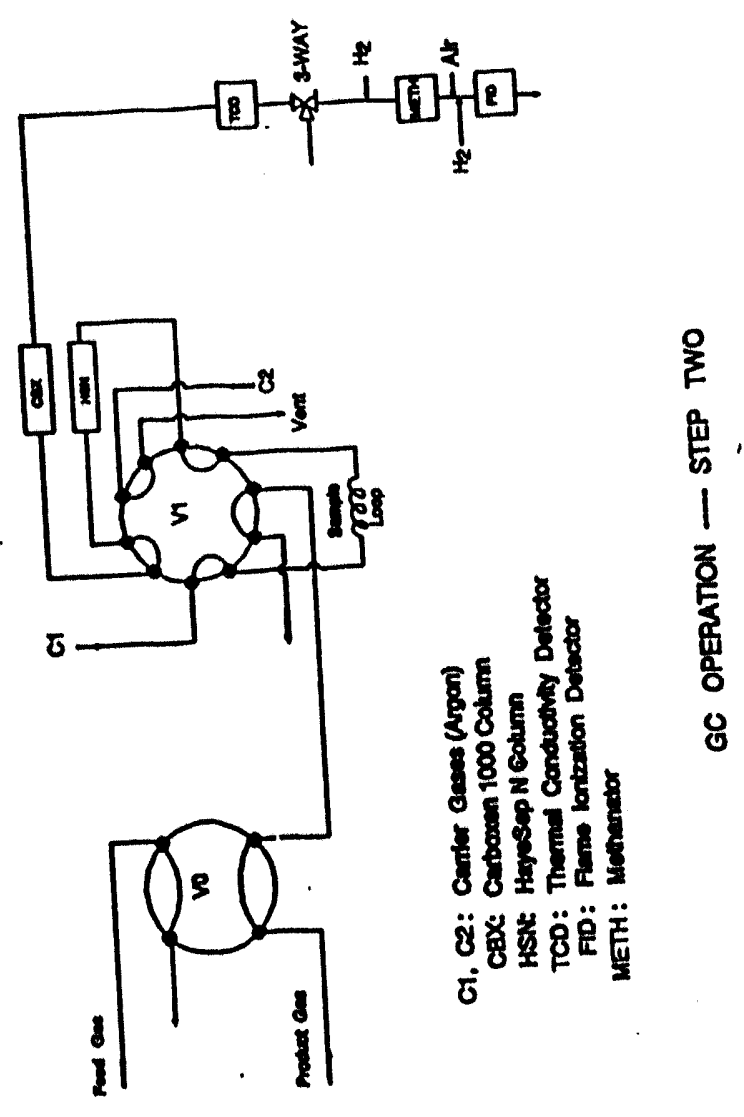

过
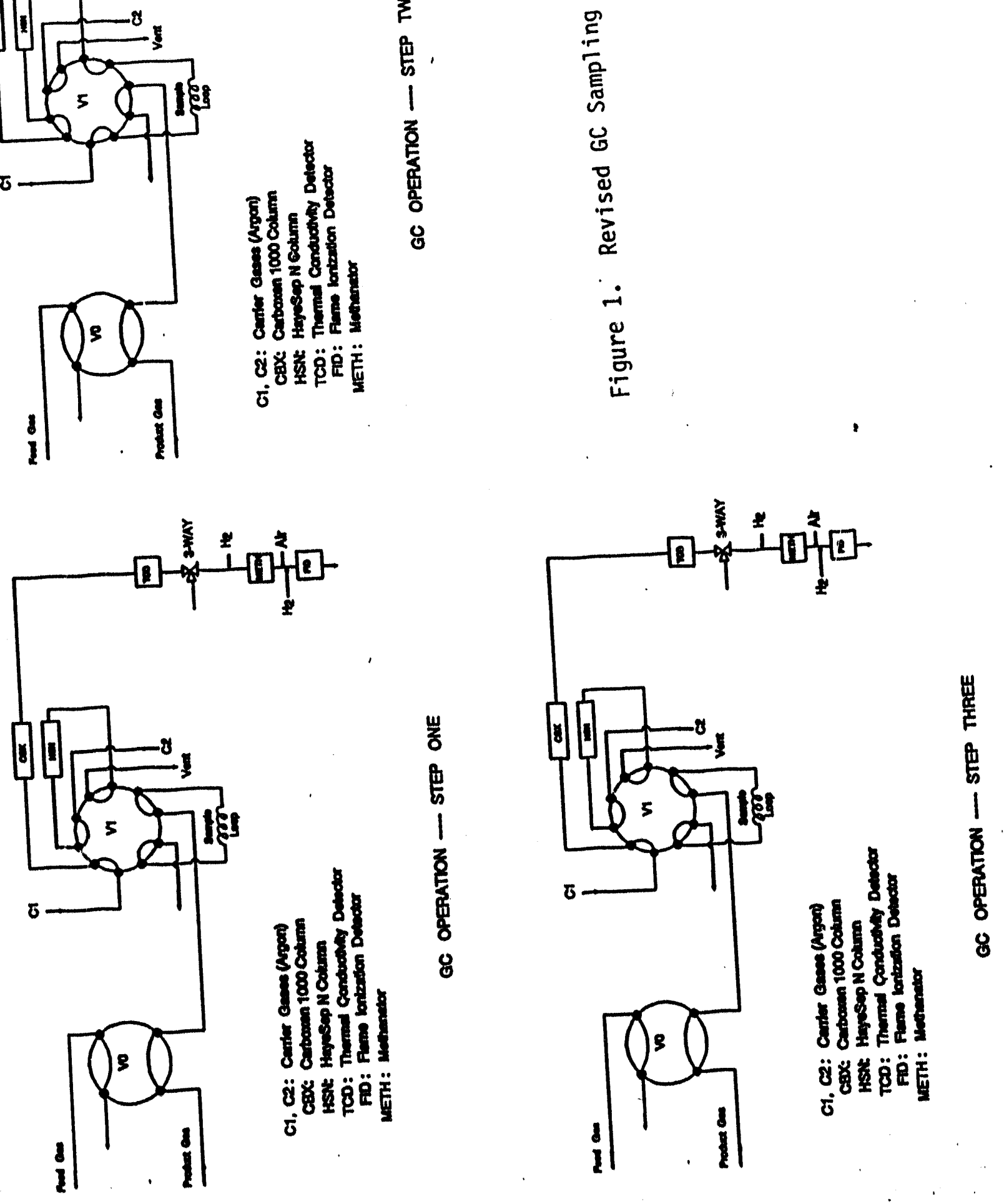
After $\mathrm{H}_{2}, \mathrm{~N}_{2}, \mathrm{CO}$, and $\mathrm{CO}_{2}$ have eluted from $\mathrm{HSN}$ but before $\mathrm{H}_{2} \mathrm{O}$ is eluted, V1 is switched to the position shown in step 3 . Note that valve positions in steps 1 and 3 are identical. Reactor product again flows into V1, through the sample loop, and to vent. $\mathrm{C} 1$ flows into V1 and then through $\mathrm{CBX}$ where separation of $\mathrm{H}_{2}, \mathrm{~N}_{2}, \mathrm{CO}$ and $\mathrm{CO}_{2}$ occurs. As these components are eluted from CBX, they pass individually through the appropriate configuration of the sample train. During this period C2 flows through $\mathrm{HSN}$ to backflush $\mathrm{H}_{2} \mathrm{O}$ to vent. When backflushing is complete and when reactor products have been analyzed, V1 is switched back to the step 2 position to begin analysis of the next sample.

GC operating conditions currently being used are summarized below:

1. Temperature of $\mathrm{V} 1$ and sample loop $55^{\circ} \mathrm{C}$

2. Column temperature $85^{\circ} \mathrm{C}$

3. TCD temperature $80^{\circ} \mathrm{C}$

4. Methanizer temperature $300^{\circ} \mathrm{C}$

5. FID temperature $250^{\circ} \mathrm{C}$

The overall time between samples can be as short as 8 minutes. $V 1$ is programmed to remain in the step 2 position for 3.2 minutes, thus providing at least 4.8 minutes to complete backflushing $\mathrm{H}_{2} \mathrm{O}$ from HSN. Retention times for the four components using the above operating conditions are:

$\begin{array}{ll}\mathrm{H}_{2} & 0.69 \mathrm{~min} \\ \mathrm{~N}_{2} & 1.26 \mathrm{~min} \\ \mathrm{CO} & 1.53 \mathrm{~min} \\ \mathrm{CO}_{2} & 6.05 \mathrm{~min}\end{array}$

This new valve and column arrangement is simpler than the previous configuration. If the ruthenium methanizer proves to be reliable over 
the long term so that the FID can be used to provide the desired low concentration sensitivity, then this new method should improve the accuracy and reliability of the analysis.

The above changes required that the analytical system be recalibrated. Additional calibration mistures were purchased to provide a wider range of concentrations than previously avallable. The compositions of seven calibration gas mixture are summarized in Table I. Combinations of these standard mixtures shown in Table II were used to develop new calibrations for both detectors. Higher concentrations were used for TCD calibration while lower concentrations were used for FID calibration. Both detectors were calibrated using intermediate concentrations to provide overlap. Quadratic constants for the new calibrations are summarized in Table III. Each calibration is based on a minimum of three concentration levels. Correlation coefficients for the new TCD calibrations are similar to those previously reported using the previous analytical method.

Three instances of calibration overlap occurred. That is, $\mathrm{CO}_{2}$ concentrations of $0.5 \mathrm{~mol}$ per cent and $0.999 \mathrm{~mol}$ percent, and a co concentration of $0.999 \mathrm{~mol}$ per cent were used to calibrate both detectors. The calibrated $\mathrm{CO}_{2}$ concentrations were within 2.58 of the actual concentration in both cases using both detectors. However, there was considerable difference between the $\mathrm{CO}$ mol per cent calculated from the TCD calibration and the actual Co concentration of the calibration gas. The CO concentration calculated using the FID calibration was quite close to the actual co concentration. This illustrates the importance of the more sensitive FID at low concentrations. 
Table I. Calibration Gas Compositions (mol percent)

Original

Standard

CO

$\mathrm{CO}_{2}$

$\mathrm{H}_{2}$.

$\mathrm{N}_{2}$

01

9.98

9.99

9.98

balance

02

$\pm 0.20$

$\pm 0.20$

$\pm 0.20$

0.050

0.100

15.04

balance

$\pm 0.001$

$\pm 0.002$

$\pm 0.30$

03

1.00

4.00

20.00

balance

$\pm 0.02$

$\pm 0.10$

$\pm 0.40$

New

Standard

$\begin{array}{lcccc}\mathrm{N} 1 & 0.099 & 0.099 & 2.99 & \text { balance } \\ & \pm 0.002 & \pm 0.002 & \pm 0.06 & \\ \mathrm{~N} 2 & 0.501 & 0.500 & 5.99 & \text { balance } \\ & \pm 0.010 & \pm 0.010 & \pm 0.10 & \\ \mathrm{~N} 3 & 0.999 & 0.999 & 11.90 & \text { balance } \\ & \pm 0.020 & \pm 0.02 & \pm 0.20 & \\ \mathrm{~N} 4 & 5.02 & 5.03 & 20.00 & \text { balance } \\ & \pm 0.10 & \pm 0.10 & \pm 0.40 & \end{array}$


Table II. Standard Gas Compositions Used for GC Calibration

$\begin{array}{ccc}\text { Compound } & \text { Detector } & \text { Calibration Mixture } \\ \text { FO } & \text { FID } & \text { O2, N1, N2, N3 } \\ \text { IICD } & \text { O1, N3, N4 } \\ \mathrm{CO}_{2} & \text { FID } & \mathrm{N} 1, \mathrm{~N} 2, \mathrm{~N} 3 \\ \mathrm{TCD} & \mathrm{N} 2, \mathrm{~N} 3, \mathrm{~N} 4 \\ \mathrm{H}_{2} & \text { TCD } & \mathrm{O} 2, \mathrm{~N} 1, \mathrm{~N} 2, \mathrm{~N} 3, \mathrm{~N} 4 \\ \mathrm{~N}_{2} & \text { TCD } & 02, \mathrm{~N} 1, \mathrm{~N} 2, \mathrm{~N} 3, \mathrm{~N} 4\end{array}$


l'able III. Quadratic Constants for GC Calibration

$$
\begin{aligned}
y_{i}= & a_{i} A_{i}+b_{i} A_{i}^{2} \\
& y_{1}=\text { mol percent } i \\
& a_{i}, b_{i}=\text { calibration constants } \\
& A_{1}=\text { chromatograph peak area } \\
& R_{i}^{2}=\text { correlation coefficient }
\end{aligned}
$$

$\begin{array}{cr}\text { Component } & \text { Detector } \\ \mathrm{CO} & \mathrm{FID} \\ \mathrm{CO}_{2} & \mathrm{TCD} \\ & \mathrm{FID} \\ \mathrm{H}_{2} & \mathrm{TCD} \\ \mathrm{N}_{2} & \mathrm{TCD} \\ & \mathrm{TCD}\end{array}$

$a_{i}$

$1.551 \times 10^{-7}$

$1.19 \times 10^{-4}$

$1.010 \times 10^{-6}$

$1.356 \times 10^{-4}$

$7.617 \times 10^{-6}$

$8.390 \times 10^{-5}$ $b_{i}$

$$
1.658 \times 10^{-15}
$$$$
-8.009 \times 10^{-11}
$$$$
-1.225 \times 10^{-13}
$$$$
3.371 \times 10^{-11}
$$$$
3.476 \times 10^{-13}
$$

$1.008 \times 10^{-11}$
$\mathrm{R}_{1}^{2}$

1.0071

1.0264

0.9865

1.0012

1.0075

0.9997 
REACTION TEST RESULTS

Near the end of the previous quarter, the initial reaction test involving sorbent calcination (one-half cycle) was completed. Eight preliminary reaction tests involving one complete calcinationcarbonation cycle were carried out during the present quarter and a summary of test conditions is presented in Table IV.

The original sorbent charge in all tests was in the carbonate form. Dolomite $\left(\mathrm{MgCO}_{3} \cdot \mathrm{CaCO}_{3}\right)$ was used in all tests except 06 where marble chips were used. The marble chips were high in $\mathrm{CaCO}_{3}$ and contained no $\mathrm{MgCO}_{3}$. The initial sorbent mass ranged from 15.8 to $20.4 \mathrm{~g}$ and three different particle size ranges were tested. A new charge of sorbent was used in all tests except 09 where the test 08 charge was subjected to a second calcination/carbonation cycle. There was no particular effort to keep tight control over these parameters since these tests were considered to be preliminary.

Calcination was carrier out by heating the sorbent to $750^{\circ} \mathrm{C}\left(800^{\circ} \mathrm{C}\right.$ in test 02 ) under flowing nitrogen at pressures ranging from 3.2 to 3.7 atm. Two nitrogen flow rates were used with the higher flow rate of 500 sccm used in the later tests. Complete calcination, as indicated by zero $\mathrm{CO}_{2}$ concentration in the reactor product, was achieved in all tests. The higher $\mathrm{N}_{2}$ flow rate was used to speed the calcination process and reduce the time required to complete the lengthy one-cycle reaction test. For example, 12.5 hours were required to complete test 03.

Carbonation test conditions were chosen on the basis of electrobalance results from Phase $I$ of this study. The reactor pressure was 1.5 atm except during the early stages of test 02 , while temperature ranged 


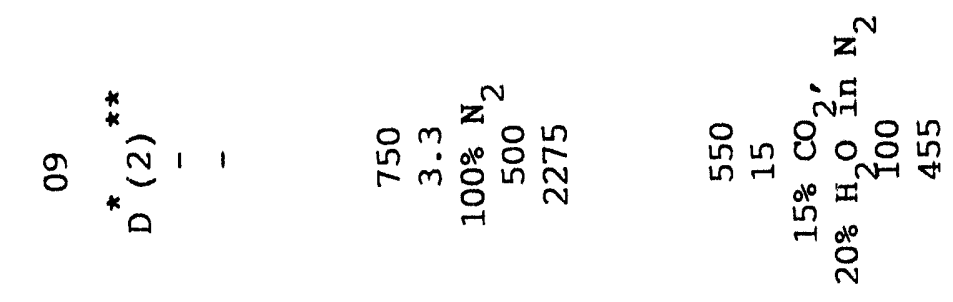

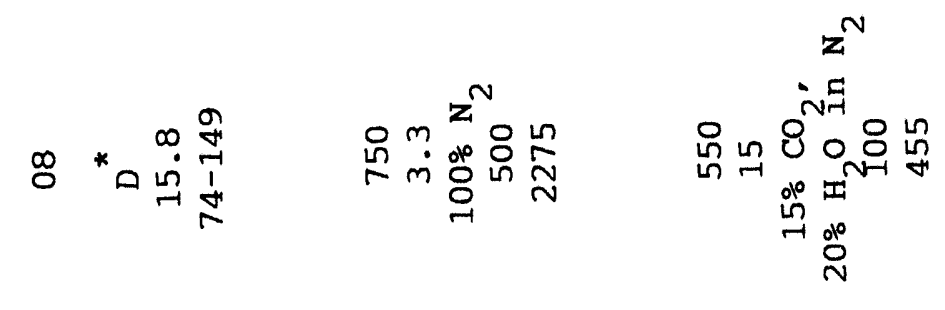

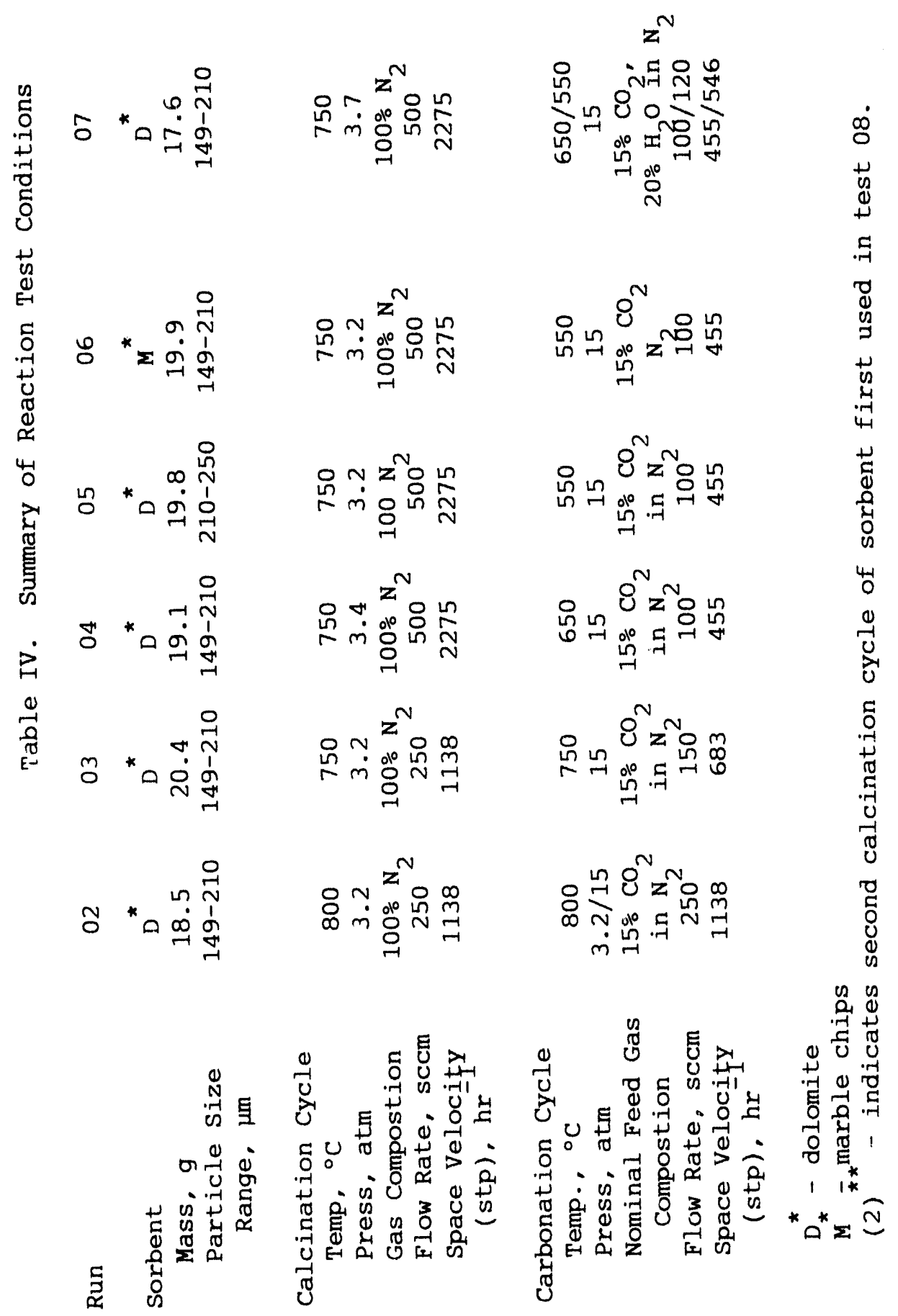


from $800^{\circ} \mathrm{C}$ to $550^{\circ} \mathrm{C}$. High fractional $\mathrm{CO}_{2}$ removal is favored at low temperature while $800^{\circ} \mathrm{C}$ is near the maximum possible carbonation temperature allowed by thermodynamics. The simplest possible gas mixture consisting of $15 \% \mathrm{CO}_{2}$ in $\mathrm{N}_{2}$ was used in tests 02 through 06 . In test $07,20 \% \mathrm{H}_{2} \mathrm{O}$ (steam) was added to the carbonation feed gas to verify our ability to inject steam into the high pressure reactor. Carbonation volumetric feed rate ranged from 250 to $100 \mathrm{sccm}$, with the lower value used in most tests to provide maximum residence time in the reactor in order to achieve high fractional $\mathrm{CO}_{2}$ removal.

Selected results from these tests are described below.

Calcination Results

The sorbent was loaded into the reactor at room temperature and the reactor was heated at a nominal $5^{\circ} \mathrm{C}$ per minute to the desired final calcination temperature. Heating was carried out under flowing $\mathrm{N}_{2}$ at the pressure and flow rate indicated in Table IV. Reactor product. during the calcination cycle was sampled at 8 or 10 minute intervals and analyzed using the gas chromatograph. Results for tests 02 through 06 referred to in the following discussion utilized the original analytical sequence involving three GC columns and two multiport sampling valves with only the TCD used for analysis. The new analytical method was implemented between tests 06 and 07 .

Reactor temperature profiles during the heating and calcination periods of test 03 are shown in Figure 2. During the early heating stages, the large mass of the reactor caused a considerable thermal lag between the set-point temperature, $T_{f}$, and the temperatures at various positions in the reactor. $T_{1}$ represents the temperature of the preheated gas just before contacting the sorbent. $\mathrm{T}_{2}$ through $\mathrm{T}_{5}$ 
FB -03

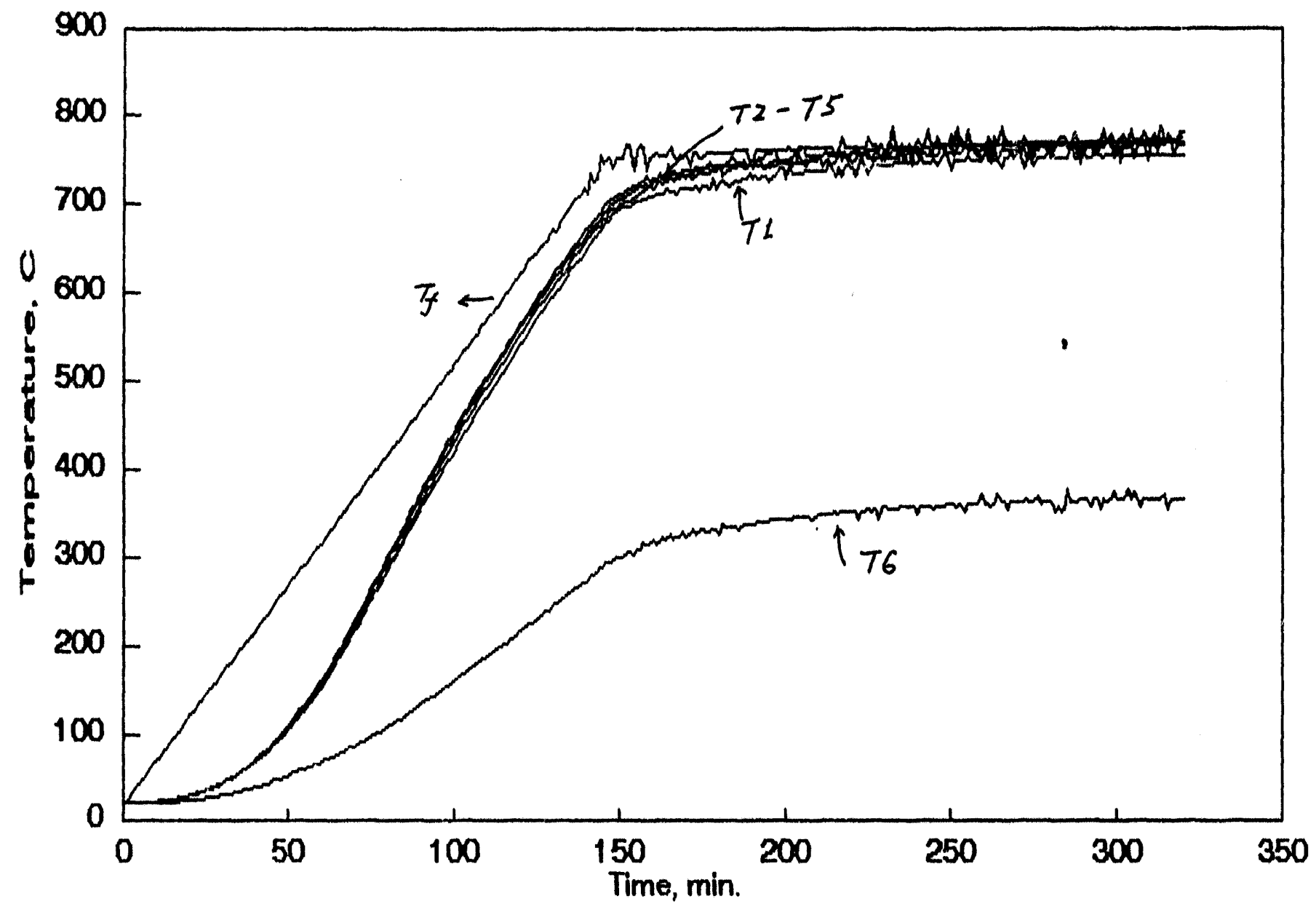

Figure 2. Reactor Temperature History During the Heating and Calcination Phases of Test 03. 
represent temperatures at various axial positions within the sorbent, with $\mathrm{T}_{2}$ near the top of the sorbent and $\mathrm{T}_{5}$ near the bottom. $\mathrm{T}_{6}$ represents the product gas temperature after it has been partially cooled just before it exits the reactor. A figure in the previous quarterly report shows the axial location of the thermocouples in more detail. After an initial period of about 30 minutes the reactor temperature begins to catch up with the set-point temperature and the temperature lag is about $70^{\circ} \mathrm{C}$ after 100 minutes. By 200 minutes when the set-point temperature was $750^{\circ} \mathrm{C}$, the reactor feed had been preheated to $\mathrm{T}_{1} \sim 740^{\circ} \mathrm{C}$, while the temperatures within the sorbent were approximately $750^{\circ} \mathrm{C}$ range $\left(\mathrm{T}_{2}\right.$ through $\left.\mathrm{T}_{5}\right)$. The product gas temperature was approximately $325^{\circ} \mathrm{C}$ at this time which provides an ample margin of safety for the high-pressure o-ring seals.

Figures 3 and 4 show $\mathrm{CO}_{2}$ concentration in the calcination product gas as a function of time from tests 05 and 06 , respectively. The most striking difference in the two figures is the sharp spike in the $\mathrm{CO}_{2}$ concentration in Figure 3 at about 150 minutes. This peak is attributed to decomposition of $\mathrm{MgCO}_{3}$ prior to decomposition of $\mathrm{CaCO}_{3}$. The sharp peak is not present in Figure 4 where the sorbent did not contain of $\mathrm{MgCO}_{3} \cdot$ Similarly, the peak was not present during the calcination phase of test 09 in which the composition of the sorbent at the beginning of the second calcination cycle was a mixture of Mgo and $\mathrm{CaCO}_{3}$

During the calcination of dolomite (Figure 3 ), the first traces of $\mathrm{CO}_{2}$ appeared after 80 minutes at $\mathrm{T} \sim 325^{\circ} \mathrm{C}$, and the calcination rate became significant after 104 minutes with $\mathrm{T} \sim 475^{\circ} \mathrm{C}$. The maximum $\mathrm{CO}_{2}$ concentration of 17.9 molo appeared in the sample taken at 144 minutes 
FB -05

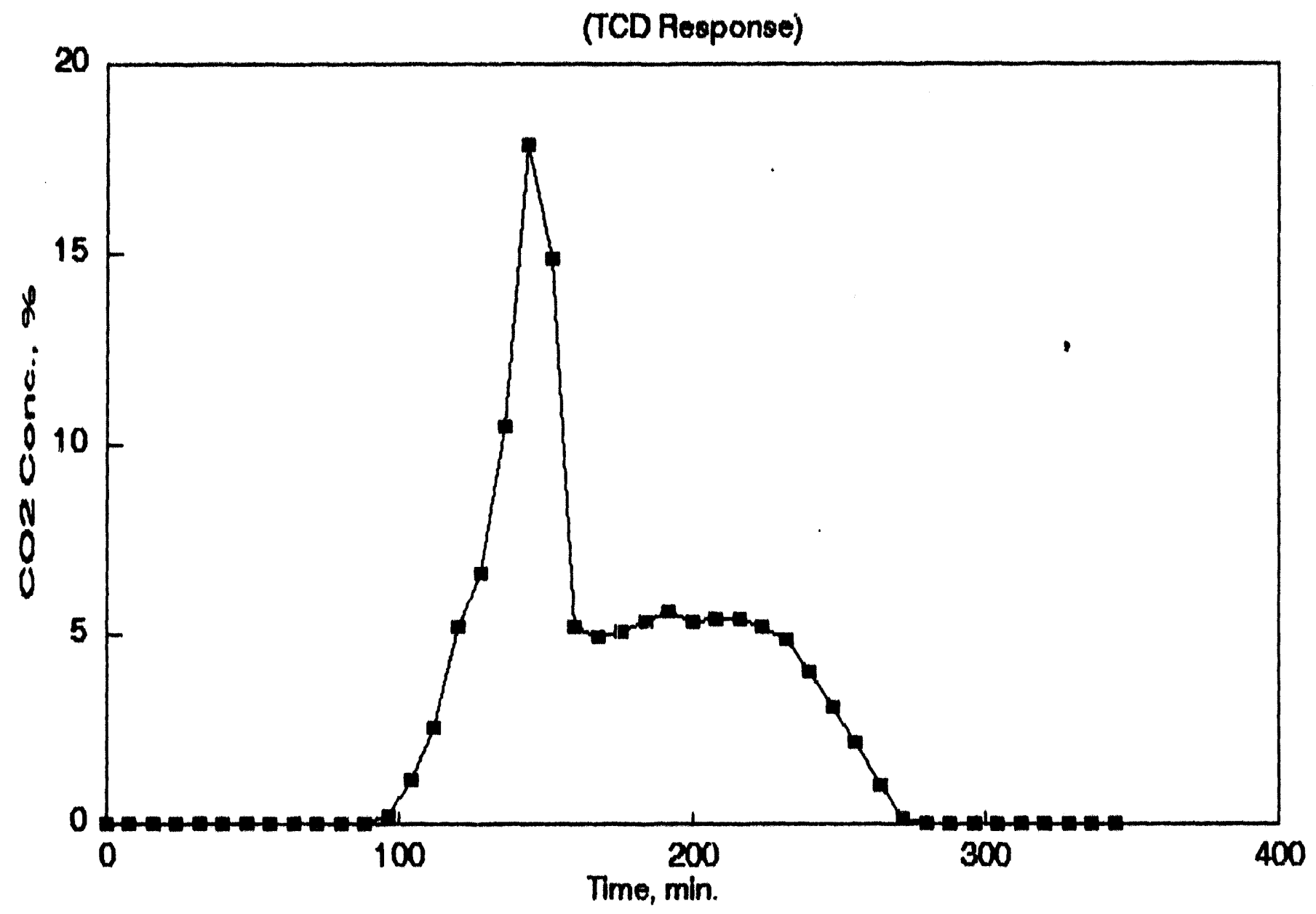

Figure 3. Mol Percent $\mathrm{CO}_{2}$ Versus Time During the Calcination Phase of Test 05. 


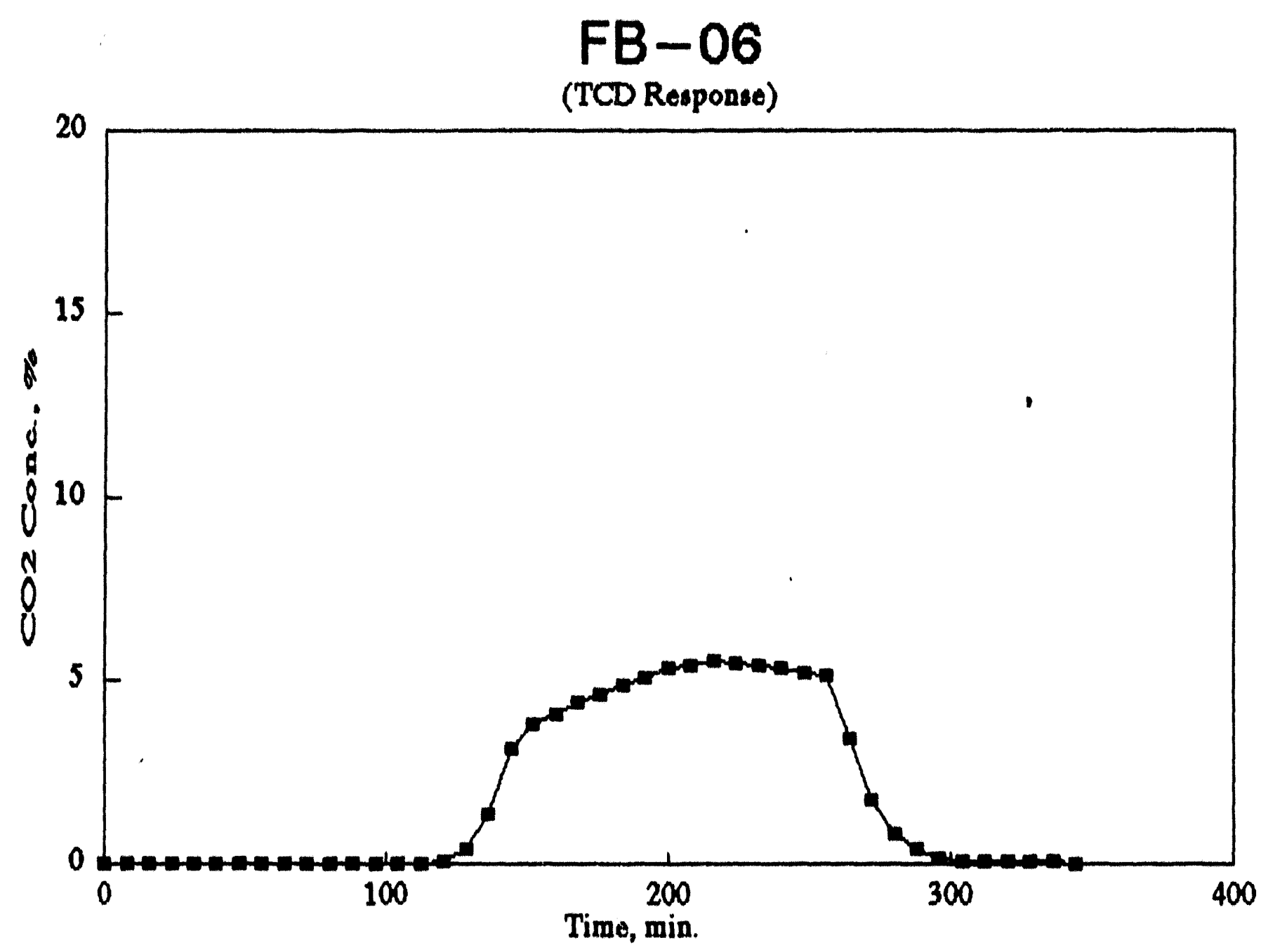

Figure 4. Mol Percent $\mathrm{CO}_{2}$ Versus Time During the Calcination Phase of Test 06 . 
$\left(\mathrm{T} \sim 700^{\circ} \mathrm{C}\right)$. Decomposition of $\mathrm{MgCO}_{3}$ is responsible for the peak and much of the early $\mathrm{CO}_{2}$. After 144 minutes the $\mathrm{CO}_{2}$ concentration decreased rapldily and leveled out at about $5 \mathrm{~mol} \mathrm{CO}_{2}$ over the time Interval 168 to 232 minutes $\left(\mathrm{T} \sim 750^{\circ} \mathrm{C}\right)$. Thereafter, the $\mathrm{CO}_{2}$ concentration decreased once again and was below the TCD detection limit after 280 minutes.

In addition to the absence of the sharp $\mathrm{CO}_{2}$ peak in Figure 4, the first appearance of $\mathrm{CO}_{2}$ was delayed by about 30 minutes until the temperature was above $500^{\circ} \mathrm{C}$. Thereafter, the $\mathrm{CO}_{2}$ concentration rose to just over 58 after $190 \mathrm{minutes}$ and remained at that level for about 60 minutes before decreasing to below the TCD detection limit at about 300 minutes. Calcination performance during the latter stages of the calcination cycle was similar in both tests 05 and 06.

Complete calcination of the $19.8 \mathrm{~g}$ of dolomite used in test 05 should produce $0.215 \mathrm{~mol}$ of $\mathrm{CO}_{2}$. Numerical integration of the $\mathrm{CO}_{2}$ concentration-time curve in Figure 3 accounts for $0.209 \mathrm{~mol}$ of $\mathrm{CO}_{2}$, corresponding to greater than $978 \mathrm{CO}_{2}$ materlal balance closure. In test 06, the 19.9 grams of sorbent should produce 0.199 mol of $\mathrm{CO}_{2}$ (assuming that the original sorbent is pure $\mathrm{CaCO}_{3}$ ). Integration of the $\mathrm{CO}_{2}$ concentration-time curve of Figure 4 accounts for $0.146 \mathrm{~mol}$ of $\mathrm{CO}_{2}$, whirh represents only about $73 \% \mathrm{CO}_{2}$ materlal balance closure. However, it should be recognized that the composition of the marble chips is not: known.

Calcination results from tests $02,03,04,07$, and 08 were qualitatively simflar to the results from test 05 shown in Figure 3. Small differences were attributed to differences in the calcination pressure and/or flow rate. The calcination results from test 09 were qualitatively similar to the Figure 4 results from test 06 . Even though 
the original sorbent was dolomite (used in test 08), no $\mathrm{MgCO}_{3}$ was reformed during the carbonation portion of test 08. Therefore, in the test 09 calcination, only $\mathrm{CaCO}_{3}$ was decomposed.

One additional topic pertaining to the calcination portion of the cycle was resolved during the quarter. As reported in the previous quarterly report, small concentrations of CO were found in the calcination product gas from test 01 . The presence of $\mathrm{CO}$ was tentatively attributed to the reaction

$$
\mathrm{C}(\mathrm{s})+\mathrm{CO}_{2}(\mathrm{~g}) \rightarrow 2 \mathrm{CO}(\mathrm{g})
$$

with the reactor tube walls serving as the carbon source. Small concentrations of $\mathrm{CO}$ continued to appear in the calcination portion of the tests completed this quarter. Co is definitely tied to the presence of $\mathrm{CO}_{2}$ in that no $\mathrm{CO}$ ls found during the heating perlod before carbonate decomposition begins. Simliarly, no $\mathrm{CO}$ is found after the $\mathrm{CO}_{2}$ concentration returns to zero at the end of carbonate decomposition. The reaction between $\mathrm{CO}_{2}(g)$ and the tube walls was confirmed as the source of $\mathrm{CO}$ in a test in which $\mathrm{CO}_{2}$ and $\mathrm{N}_{2}$ were fod at high temperature to the reactor which contained no sorbent. Co was also found in the reactor product under these conditions.

\section{Carbonation Results}

The simplest carbonation gas composed of 15 mols $\mathrm{CO}_{2}$ in $\mathrm{N}_{2}$ was used in tests 02 through 06 . Carbonation temperature and feed rate were varied, and the carbonation reaction proceeded as expected. $20 \%$ steam was added to he foed gas beginning in test 07 to verify our ability to infect steam into the high pressure reactor. The tests were successful In that respect, but no quantitative reaction data was obtalned because 
of gas leaks in tests 07 through 09. In addition to proving our abllity to infect steam at high pressure, it is important to note that small amounts of $\mathrm{H}_{2}$ were found in the reactor product during the carbonation cycle. The only possible source of the $\mathrm{H}_{2}$ is by the water-gas shift reaction with $\mathrm{H}_{2} \mathrm{O}$ in the feed gas reacting with $\mathrm{Co}$ formed by the reaction of $\mathrm{CO}_{2}$ with the reactor walls. This result, although preliminary and only qualitative, is significant in that it does prove that the water-gas shift reaction will occur at the reaction conditions of intereat.

Quantitative results which were obtained from tests 02 through 06 are summarized below. Figure 5 and 6 show the $\mathrm{CO}_{2}$ breakthrough curves from tests 05 and 06 , respectively. In test 05 (Figure 5), the carbonation gas consisting of $15 \mathrm{CO}_{2}$ in $\mathrm{N}_{2}$ (nominal) was fed to the reactor beginning at 390 minutes. The $\mathrm{CO}_{2}$ concentration in the product gas remained below the TCD detection limit for 65 minutes. Thereafter, the $\mathrm{CO}_{2}$ concentration increased rapidly and the traditional breakthrough curve was formed. The final $\mathrm{CO}_{2}$ composition of the product gas was about 17 mol 8 , somewhat higher than the nominal 15 mol fod. The total quantity of $\mathrm{CO}_{2}$ removed from the gas phase during carbonation was 0.066 mols, which corresponds to 598 conversion of cao.

The $\mathrm{CO}_{2}$ breakthrough curve from test 06 (Figure 6) is qualitatively similar to that for test 0.5 (Figure 5). Carbonation gas was introduced after 380 minutes and $\mathrm{CO}_{2}$ in the product: gas was below the TCD detection limit for 68 minutes. The first significant amount of $\mathrm{CO}_{2}$ appeared at about $t=520$ minutes, and the concentration rapldly increased to about 18 after 560 minutes, The total quantity of $\mathrm{CO}_{2}$ removed from 


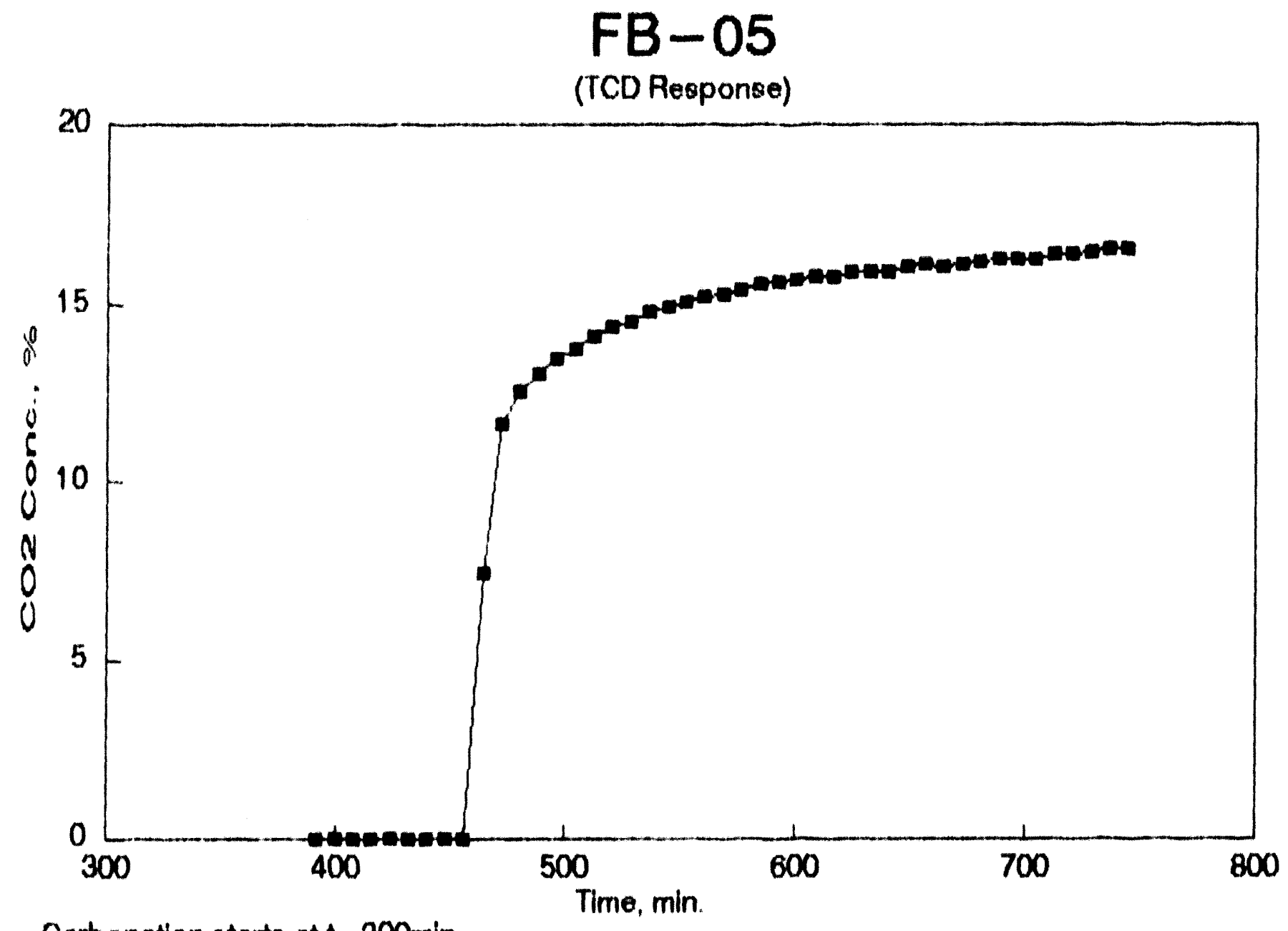

Carbonation starts at $t=390 \mathrm{~min}$.

Figure 5. $\mathrm{CO}_{2}$ Breakthrough Curve During the Carbonation Phase of Test 05 . 


\section{FB-06}

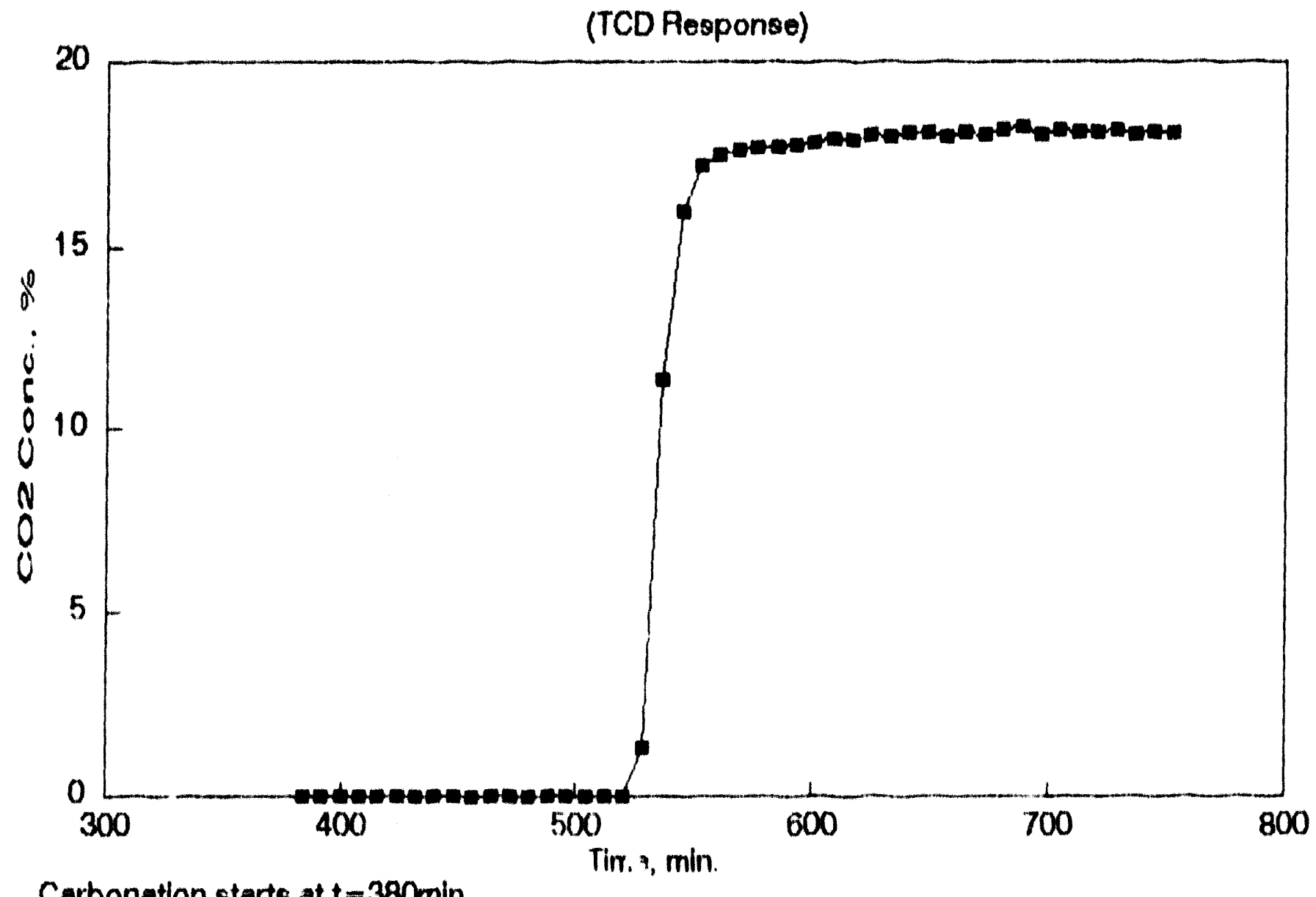

Carbonation starts at $t=380 \mathrm{~min}$.

Figure 6. $\mathrm{CO}_{2}$ Breakthrough Curve During the Carbonation Phase of Test 06. 
the gas phase during carbonetion was 0.116 mols which corresponds to replacement of 798 of the $\mathrm{CO}_{2}$ proluced during calcination.

Tests 02 through 05 represent a serles in which the primary variable was carbonation temperature. Test 02 was begun at a carbonation pressure of 3.2 atmospheres but the pressure was soon increased to 15 atmospheres. In addition the volumetric feed rate was changed during the serles. Netther of these changes, however, should have a significant effect on the prebreakthrough $\mathrm{CO}_{2}$ concentration. The experimental prebreakthrough $\mathrm{CO}_{2}$ partial pressure as a function of temperature is shown in Figure 7 , along with the equilibrium $\mathrm{CO}_{2}$ partial pressure. Because carbonation is exothermic arid reversible, the $\mathrm{CO}_{2}$ equilibrium partial pressure increases with temperature. The experimental results follow the same pattern, but the experimental values are three to four times larger than the equilibrium values. Fallure to achieve equilibrium is due to finite rate of the reaction. In principle, the two values can be brought closer together by increasing the reactor volume and/or decreasing the volumetric flow rate. 


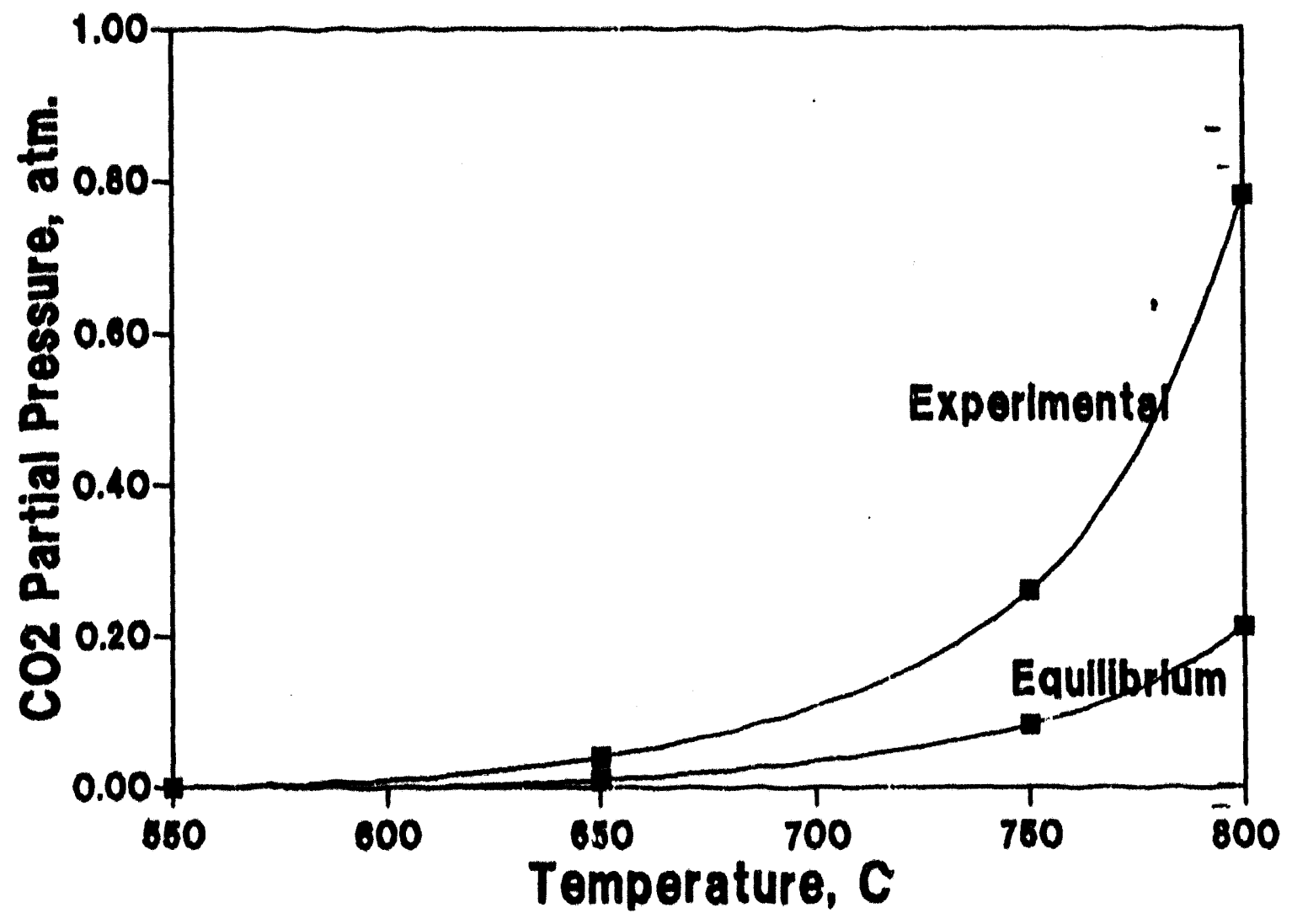

Figure 7. Prebreakthrough Partial Pressure of $\mathrm{CO}_{2}$ From the Fixed-Bed Reactor. 

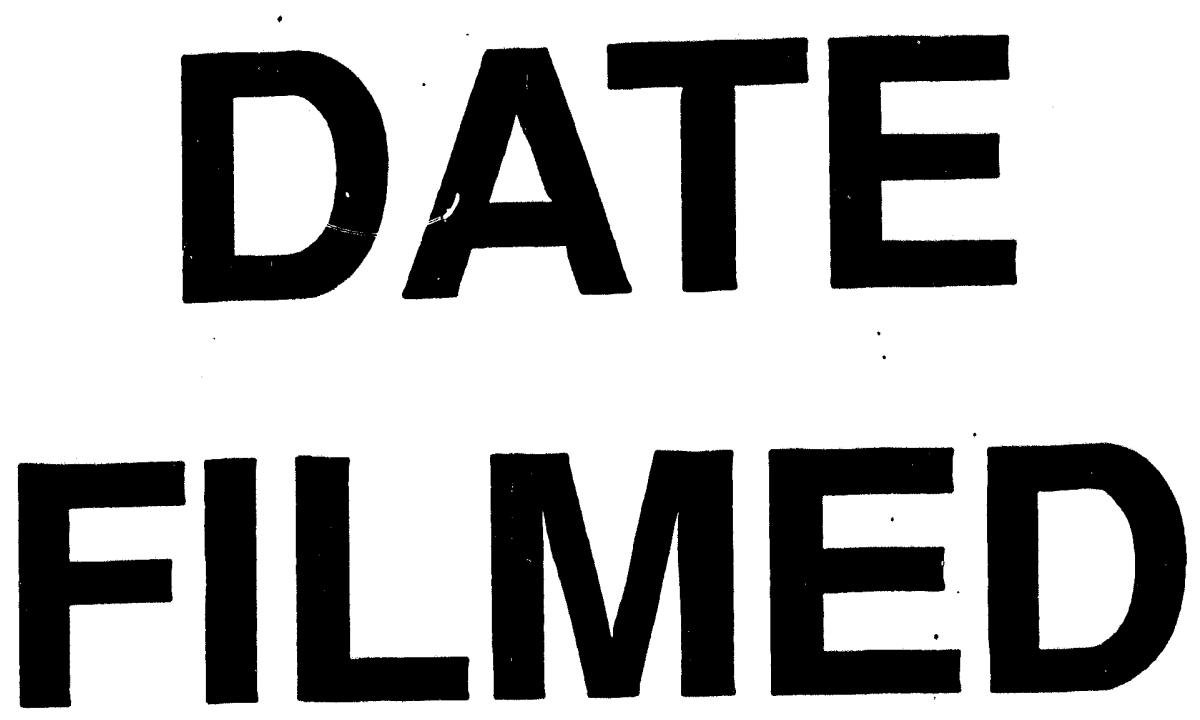

$11 / 4 / 93$
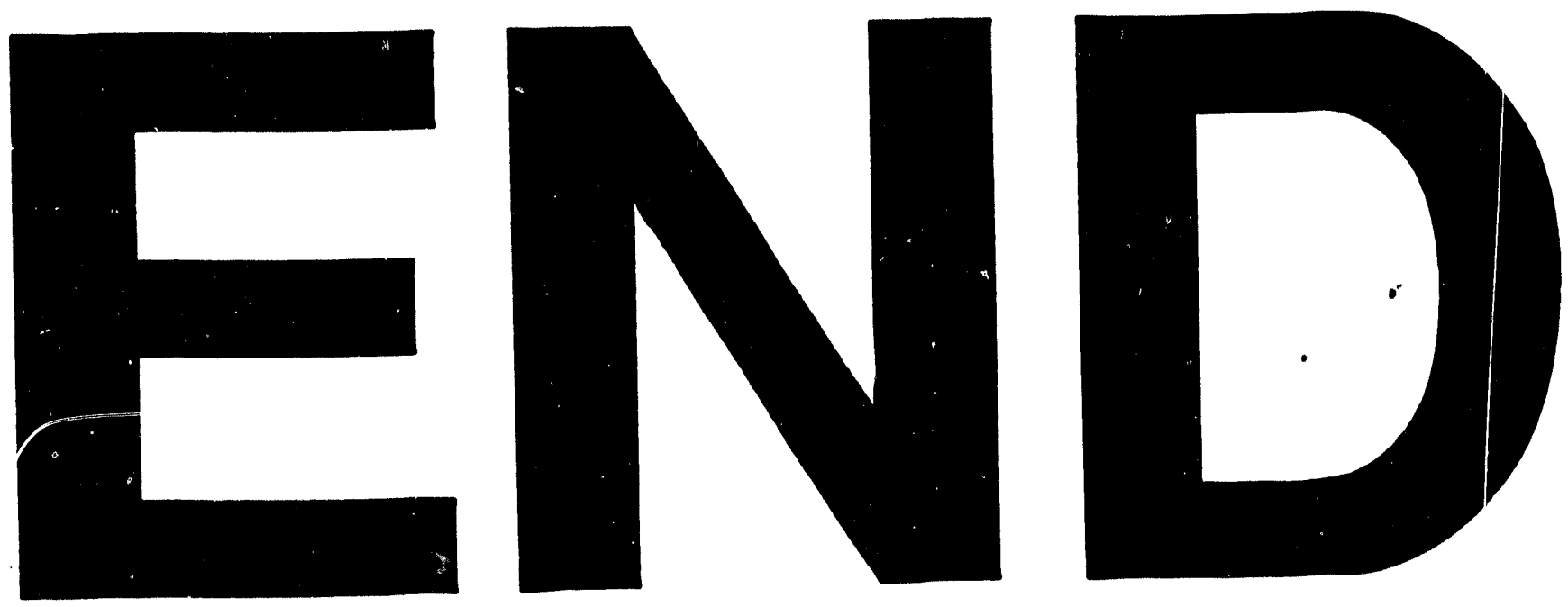
